\title{
O TESTAMENTO ORDINÁRIO COMO ALTERNATIVA AO PLANEJAMENTO SUCESSÓRIO EM TEMPOS DE PANDEMIA
}

\author{
Marina Bonissato Frattari ${ }^{1}$ \\ Kelly Cristina Canela ${ }^{2}$
}

\section{RESUMO}

O planejamento sucessório e patrimonial surge como uma alternativa organizacional ao patrimônio do titular dos bens e à família, sendo uma forma de efetivar a autonomia da vontade. Com isso, considerando a realidade da Covid-19, a presente pesquisa objetiva investigar as espécies de testamento ordinário no atual cenário de pandemia no Brasil e suas características, bem como se houve um considerável aumento do número de testamentos no último ano no país observando o contexto de vulnerabilidade do Coronavírus. Para isso, parte de uma metodologia com abordagem qualitativa, método dedutivo e técnicas bibliográfica e documental.

Palavras-chave: Testamento ordinário; Planejamento sucessório; Planejamento patrimonial; Testamento particular; Covid-19.

\section{THE ORDINARY WILL AS AN ALTERNATIVE TO SUCCESSION PLANNING IN TIMES OF PANDEMIC}

\begin{abstract}
Succession and estate planning is an alternative to organize the family and the assets of the owner of the estate. It is also a way to effectuate the autonomy of choice. Thus, considering the reality of Covid-19, this research study the species of ordinary will in the current pandemic scenario in Brazil and its characteristics, also study whether there has been a considerable increase in the number of wills in the country in 2020 observing the context of vulnerability of the Coronavirus. For this, it has a methodology with a qualitative approach, deductive method and bibliographic and documental techniques.
\end{abstract}

Keywords: Ordinary will; Succession planning; Estate planning; Private will; Covid-19.

\section{Introdução}

Ao tratar de sucessão, intrinsecamente o tema relaciona-se a transmissão de bens, pois há um detentor de um patrimônio que pretende deixá-lo a outrem. No direito brasileiro é o Código Civil que trata e regula o assunto, podendo a transmissão se dar causa mortis ou inter vivos, a título oneroso ou gratuito.

\footnotetext{
1 Mestranda em Direito pela Universidade Estadual Paulista - FCHS - Franca; Pós-graduanda em Direito Processual Civil Empresarial pela Faculdade de Direito de Franca.

${ }^{2}$ Doutora na Área de Direito Privado pela Faculdade de Direito da Universidade de São Paulo e professora do Departamento de Direito Privado da Universidade Estadual Paulista - FCHS - UNESP.
} 
O direito das sucessões é composto por uma miscelânia de instrumentos jurídicos aptos a transmitir a titularidade de bens, direitos ou obrigações de uma pessoa que faleceu aos seus sucessores, podendo eles serem legítimos ou testamentários.

É importante destacar o direito das sucessões, pois no decorrer da vida, todo indivíduo já deve ter se perguntado, ao menos uma vez, a quem ou como ficarão seus pertences depois que ele partir. Tal dúvida gera incertezas, inseguranças e pretensões de quem não consegue prever o futuro. Contudo, tais receios podem ser diminuídos se houver um planejamento sucessório e patrimonial adequado à realidade de cada sujeito. Por realidade, relaciona-se às relações familiares, fraternas, patrimoniais, societárias, enfim, tudo o que rodeia e integra o cotidiano patrimonial de alguém.

Em tempos sombrios de pandemia, em que um inimigo invisível atinge comunidades inteiras, desfaz laços familiares e fraternos, abalou a economia mundial e inaugurou crises políticas em vários países, notou-se que a vida é um sopro, pois eventos imprevisíveis podem vulnerabilizar vários os indivíduos. Não diferente, assombra a todos que querem o mínimo de proteção aos seus pares.

Neste ínterim, o planejamento sucessório e patrimonial surge como uma alternativa organizacional ao patrimônio do titular dos bens e até mesmo à família como um todo, bem como apresenta ser uma forma de efetivar a autonomia de vontade.

Com instrumentos diversos, o planejamento sucessório pode evitar dilapidação patrimonial, lide entre a família e os herdeiros e o alto custo com o processo de inventário que poderá se estender por anos. Contudo, dentro do planejamento sucessório e patrimonial, o testamento tem se mostrado bastante eficaz na destinação de bens e manifestação de última vontade do autor da herança.

É sobre o referido instrumento, considerando a atual realidade pandêmica causada pela Covid-19, que a presente pesquisa debruça seus esforços. É objetivo, portanto, investigar as espécies de testamento ordinário e suas características, a fim de prever se são elas uma alternativa ao planejamento sucessório no atual cenário de pandemia no Brasil, bem como se houve um considerável aumento do número de testamentos no último ano no país considerando o contexto de vulnerabilidade do Coronavírus.

Todavia, vale ressaltar que não é alvo do presente estudo discutir a igualdade quantitativa e qualitativa da partilha-testamento e a contradição entre legítima sucessória e autonomia privada. Apenas espera-se discutir alternativa legal cabível à realidade excepcional 
causada pelo vírus que assola a saúde e a segurança de todo o planeta, especialmente no Brasil.

Para isso, partiu-se de uma metodologia com abordagem qualitativa, método dedutivo e técnicas bibliográfica e documental, vez que se não se preocupou com levantamentos numéricos, mas sim com dados subjetivos e já publicados, como a análise do texto do Código Civil, da doutrina vigente, e de dados numéricos publicados por órgãos notariais.

\section{O testamento e suas espécies}

Enquanto na sucessão legítima há uma ordem de sucessão hereditária, considerando os herdeiros necessários (art. 1829 do Código Civil) e os legatários (art. 1839 do CC), na sucessão testamentária haverá a primazia da última vontade, ou seja, a vontade do de cujos prevalecerá para destinação de seus bens.

Contudo, a autonomia privada não é absoluta, devendo observar 50\% do patrimônio que será destinado obrigatoriamente aos herdeiros necessários. Havendo a falta destes, poderá o falecido deixar a totalidade de seus bens a quem lhe convier.

A atual legislação civil não define o testamento, coube a doutrina ${ }^{3}$ essa função. Ao Código Civil ficou a função de descrever as possibilidades testamentárias. Inclusive, ressaltase que embora o mais comum seja o aspecto patrimonial, o testamento não se reduz a tal, podendo tal instrumento jurídico servir, por exemplo, para reconhecimento de um filho (art. 1609, inciso III do CC) (TARTUCE; SIMÃO, 2013, p. 286-287). Não existe, pois, relação necessária entre patrimônio e testamento, podendo ser de aspecto patrimonial ou extrapatrimonial.

Para testar, o sujeito deve ser pessoa física, capaz, cabendo a nulidade testamentária daquele incapaz absolutamente (art. 166, I do CC). Todavia, ao menor púbere, relativamente incapaz nos moldes do artigo 4, inciso I do CC, cabe a possibilidade de testar, sem que haja qualquer assistência. "Aliás, se a assistência fosse necessária, o caráter personalíssimo e

\footnotetext{
${ }^{3}$ Nas palavras de Pontes de Miranda, citadas por Flávio Tartuce, pode-se definir testamento como: "O testamento (diz-se) é ato pelo qual a vontade de um morto cria, transmite ou extingue direitos. Porque 'vontade de um morto cria', e não 'vontade de um vivo, para depois da morte'? Quando o testador quis, vivia. Os efeitos, sim, como serem dependentes da morte, somente começam a partir dali. Tanto é certo que se trata de querer de vivo, que direitos há (excepcionalíssimos, é certo), que podem partir do ato testamentário e serem realizados desde esse momento. Digamos, pois, que o testamento é o ato pelo qual a vontade de alguém se declara para o caso de morte, com eficácia de reconhecer, criar, transmitir, ou extinguir direitos" (PONTES DE MIRANDA, 1972, apud TARTUCE, 2011, p. 1248).
} 
revogável do testamento estaria bastante comprometido, o que até poderia ser tido como motivo de nulidade do testamento [...]” (TARTUCE; SIMÃO, 2013, p. 290).

Além dos incapazes, aqueles que, no ato de testar não tiverem pleno discernimento, não poderão fazê-lo (GONÇALVES, 2016, p. 238). Neste diapasão, para testar há dois requisitos principais: a vontade e a inteligência (GONÇALVES, 2016, p. 237).

O Codex Civil vigente admite como forma de testamento aquela ordinária (três espécies) e a especial (também três espécies). Na primeira categoria, é possível a realização de testamento público, cerrado ou particular (art. 1862 do CC); já na segunda, as possibilidades dizem respeito aos testamentos marítimo, aeronáutico e militar (art. 1886 do CC). Vale ressalvar que por não ser alvo dos estudos deste trabalho, a atenção será destinada a primeira categoria apresentada.

Quanto à forma, esta representa "um pressuposto necessário ao negócio jurídico testamentário. Testamento que não obedecer à norma sobre forma - que é cogente, de ordem pública - é nulo de pleno direito e não tem efeito algum" (GONÇALVES, 2016, p. 257). Assim, aquele contrato testamentário que não obedecer às solenidades do artigo 166, incisos IV e V do CC, será nulo de pleno direito.

Lado mesmo, aos testamentos ordinários, deve haver a presença de duas testemunhas nos testamentos público e cerrado (arts.1864, II e 186, I do CC, respectivamente), e três no instrumento particular (art. 1876, $\S 2^{\circ}$ do CC). Ainda, pode o testamento público prescindir de testemunhas instrumentárias ${ }^{4}$ (art. 1865 do CC); bem como não há a necessidade de o testador ler o texto testamentário nos testamentos públicos e cerrados (arts. 1864, II; 1868 do CC) (BRASIL, 2002).

Quanto ao testamento público, previso nos artigos 1864 a 1867 do CC, este tem como principal característica a competência de quem o redige. Deve ser feito, portanto, por tabelião de notas ou seu substituto legal. Tal instrumento deve ater-se a identidade do testador e a sua sanidade mental, que deve ser eminente (MONTEIRO, 2003, p. 134).

Também, deve o testador rubricar todas as páginas do livro de notas, cujo texto deve ser escrito e em português. Ao final, o conteúdo do testamento deve ser lido pelo tabelião em voz alta ao testador e as suas testemunhas se for desejo destes (art. 1864, inciso II do CC).

\footnotetext{
${ }^{4}$ Testemunha instrumentária pode ser conceituada pela doutrina, em síntese, como "aquela pessoa que assiste a determinado fato contestando ou dele tem conhecimento, e é chamada a juízo a fim de depor desinteressadamente sobre o que souber a seu respeito. Aquele que, reconhecidamente idôneo e previamente convocado, se acha presente à conclusão de ato jurídico, para cuja autenticidade e formalidades extrínsecas concorre com sua assinatura" (CAMPOS, 1977, p.121).
} 
Caso o testador não saiba assinar, o tabelião deve constar a ocorrência, não precisando que ninguém assine em seu lugar. Se se tratar de pessoa cega ou surda, mas que saiba escrever, esta deverá cumprir com o ato da assinatura. No caso de pessoa surda e que saiba ler, este deverá ler o documento antes de ser assinado. E em caso de deficientes visuais, o testamento deverá ser lido duas vezes (uma por tabelião e a outra por uma das testemunhas). Todas essas circunstâncias devem constar no testamento (TARTUCE; SIMÃO, 2013, p. 300).

Quanto à segurança do testamento público, a grande vantagem é que este se manterá seguro em cartório, pois ficará arquivado, sendo de grande chance seu cumprimento. Sua desvantagem, por outro lado, é o custo, que nem sempre pode ser arcado pela parte (TARTUCE; SIMÃO, 2013, p. 302).

$\mathrm{Na}$ atual realidade pandêmica, houve flexibilização quanto à atuação dos cartórios de nota. Com o provimento da Resolução n 100 do Conselho Nacional de Justiça, passou a ser permitido o ato notarial eletrônico, cujo objetivo é primar pela segurança civil daqueles que precisam de serviços cartorários, bem como de seus funcionários.

Conforme o artigo $3^{\circ}$ da referida Resolução (BRASIL, 2020), deve-se obedecer, contudo, alguns requisitos para que tais atos tenham validade. Dentre eles estão as obrigatoriedades de realizar o pleito por videoconferência notarial para captação do consentimento das partes sobre os termos do ato jurídico, haver a concordância expressada pelas partes com os termos do ato notarial eletrônico, ter a assinatura digital pelas partes, exclusivamente através da plataforma e-Notariado, ter a assinatura do Tabelião de Notas com a utilização de certificado digital ICP-Brasil e primar pelo uso de formatos de documentos de longa duração com assinatura digital.

Ao tabelião de notas compete a lavratura do testamento público e a aprovação do testamento cerrado (VELOSO, 2003, p. 1561). O testamento cerrado, no que lhe diz respeito, é aquele escrito pelo testador ou por uma pessoa de sua confiança, que tenha obedecido ao seu pedido. Deve ser assinado pelo testador e posteriormente estregue ao tabelião (art. 1868, caput do CC).

Esta espécie testamentária tem como principal característica o segredo. Ou seja, como ele só será lido após o falecimento do testador, o seu conteúdo é um mistério, não sendo conhecido por terceiros (nem necessariamente pelo tabelião) (TARTUCE; SIMÃO, 2013, p. 303). 
Aqui todas as páginas devem ser assinadas pelo testador, como traz a redação do 1868, parágrafo único do CC (BRASIL, 2002). A ausência de assinatura anula o documento. No auto de aprovação, deverá haver duas testemunhas e não há a necessidade de conhecer o conteúdo material do documento. $\mathrm{O}$ auto de aprovação é "um instrumento público, um ato notorial, e não tem o objetivo de examinar e confirmar o conteúdo do testamento, de suas clausulas e disposições [...]" (VELOSO, 2003, p. 1565). Este auto é assinado pelo testador, as duas testemunhas e o tabelião.

No caso de surdo-mudo ou só mudo, o testamento deverá ser escrito à próprio punho (art. 1873 do CC), assinado em todas páginas e identificado no envelope que se trata de testamento. Ao ser entregue ao tabelião, são necessárias duas testemunhas que acompanhem o feito.

Após a lavratura do auto, este será dobrado junto ao testamento e colocado em um só envelope, que deverá ser "cerrado e cosido com cinco pontos de retrós, segundo praxe cartorária, lacrando-se o testamento nos pontos de costura” (DINIZ, 2005, p. 213).

Após o feito, o testamento ficará com o testador, sendo lançado em livro notarial apenas a nota do lugar e data de reconhecimento de sua aprovação (art. 1874 do CC). Ressalva-se que a segurança o documento fica ao encargo do testador, o que prejudica sua integralidade, podendo este sumir, ser roubado, extraviado ou sofrer algum acidente de força maior ou caso fortuito. Ainda, caso haja o rompimento do lacre, haverá a revogação do testamento pelo juiz no inventário, nos moldes do artigo 1875 do Código Civil (BRASIL, 2002).

Em se tratando de testamento particular, sua principal característica é a não participação de qualquer funcionário do Estado. Assim, conclui-se que é o próprio testador que redige, lê e assina o documento (HIRONAKA, 2003, p. 287).

Como requisito essencial, há a necessidade da presença e assinatura de três testemunhas e sua escrita deve ser por parte do testador, sob pena de nulidade, bem como a assinatura a pedido deste também é nula, sendo ato personalíssimo. Por seu turno, Zeno Veloso alude que a ausência de testemunhas incentivaria o uso do testamento particular pelos brasileiros, o que não faz parte da cultura nacional (VELOSO, 2006, p. 1571).

Nada impede que o testamento particular seja em língua diferente da brasileira, contudo, todas as testemunhas devem compreender a língua escrita, sob pena de nulidade (art. 
1880 do CC). Entretanto, não há a necessidade de datar o documento ou constar o local da redação (VENOSA, 2015).

Posteriormente, a época da abertura do testamento em processo de inventário, deve-se verificar judicialmente a autenticidade e veracidade do contrato. Serão chamados a inquirição os herdeiros, legatários e as testemunhas que assinaram o documento (art. 1877 e 1878 do CC). A estas últimas poderão ser arguidas perguntas sobre a forma do testamento, ou seja, se foi feito a leitura e se a assinatura constante no documento realmente é delas (DINIZ, 2005, p. 217).

Nota-se que o rigor formal do testamento é critério absoluto de validade. Isso acontece, pois, não estando mais o testador vivo, sua vontade jamais será esclarecida (NEVARES, 2020, p. 352-353). Qualquer omissão para o ato de última vontade passará despercebida. Tendo como palavras chave a autonomia privada e a disposição de vontade, cabe ao testador esclarecer suas intenções ao elaborar o instrumento que tratará sobre a disposição patrimonial após sua morte.

O testamento, de modo geral, é um instrumento que determina a delação sucessória mortis causa, obedecendo a autonomia privada do titular do patrimônio, mas também o limite da legítima. Como não há hierarquia entre as formas testamentárias, sua função promocional permite o exercício qualitativo da autonomia privada em direção à tutela da pessoa humana (SILVA, 2019, p. 182-183).

Em outras palavras, é possível dizer que pode ocorrer tensões aparentes entre os princípios que tutelam o testamento e outros que devem imperar na sucessão. Entretanto, por conta do equilíbrio dos interesses dos envolvidos, deverá prevalecer a vontade do testador (NEVARES, 2020, p. 332).

A título de exemplo, pode-se citar um testamento que determina a divisão dos bens considerando os vínculos dos beneficiários quanto a certos bens da herança. Neste caso, há potencial ofensa à isonomia qualitativa da quota parte dos herdeiros (NEVARES, 2020, p. 333)

Lado outro, embora o Código Civil vigente trate o testamento como um instrumento vantajoso a disposição de vontade, é preciso trazê-lo à realidade atual. As modalidades apresentadas de testamento "pressupõem a presença do testador em conjunto com outras pessoas" (NEVARES, 2020, p. 354). Assim, nenhuma modalidade exposta parece ser 
adequada à realidade de isolamento social, nem mesmo os testamentos especiais, por não obedecerem às hipóteses de cabimento.

Em tempos atuais, cuja falta de integração social não poupou nenhuma área da vida cotidiana ou classe social, “o desejo de planejar a sucessão hereditária está presente no íntimo de muitas pessoas" (NEVARES, 2020, p. 354). Visto isso, houve a flexibilização, por parte de alguns Estados, quanto ao regulamento no período pandêmico. Atos e recepções de documentos ocorrem de modo remoto ${ }^{5}$.

Há, contudo, uma excepcionalidade presente no Código Civil que pode ser uma alternativa ao cenário contemporâneo. Para os testamentos particulares, considerando situações excepcionais (art. 1879 do CC), é possível que o testador redija o documento sem que haja a presença das testemunhas. Tal situação é extrema.

Vale ressalvar que esta espécie de testamento teve inspiração no Código Civil alemão (BGB), que no artigo 2250, regula o Nottestament (testamento de emergência) (VELOSO, 2019, p. 658). No direito nacional só veio a aparecer na Codificação Civilista de 2002. Para parte da doutrina, como exposto a seguir, trata-se não de uma subespécie do testamento ordinário, mas sim de um testamento especial, usado apenas em situações extremas.

\begin{abstract}
Trata-se de uma inovação, e muito importante. O que regula, na verdade, não é um subtipo, uma subespécie de testamento particular, porém, uma outra forma de testamento especial. É uma forma simplificada, que deve ser escrita de próprio punho, não se admitindo, portanto, a utilização de meios mecânicos, e assinada pelo testador. Não requere testemunha alguma. Mas só pode ser elaborado em 'circunstâncias excepcionais'. [...] morrendo o testador, o testamento será apresentado ao juiz, e poderá, a critério deste, ser confirmado (VELOSO, 2019, p. 659).
\end{abstract}

Como exposto, suas regras peculiares devem ser obedecidas, vez que a comprovação de veracidade e autoria precisa ser certeira. Assim, o testamento do artigo 1879, denominado "hológrafo", deve ser redigido a mão, assinado e, como exposto adiante, terá prazo de validade, pois seu critério de existência é um estado extremo, que dificulta ou impede a realização das outras espécies testamentárias, sendo esse um tipo subsidiário de testamento.

\footnotetext{
${ }^{5}$ É preciso ressaltar que a Resolução ${ }^{\circ} .100$ do CNJ nada traz sobre as especificidades do testamento, ou seja, há latente omissão normativa sobre como os cartórios devem agir quanto à recepção de documentos para elaboração ou reconhecimento testamentário. A normativa em tela trouxe orientações gerais, mas dúvidas à sua execução podem surgir em casos específicos, que denotam de grande solenidade, como o testamento, o que futuramente pode gerar controvérsia quanto à validade do documento e possível lide aos envolvidos na sucessão patrimonial, não executando a vontade do de cujos. Portanto, uma norma cujo objetivo era proteger a saúde pública ao permitir a realização remota de atos notariais, pode não ser benéfica devido a sua falta de especificidade ao tratar o testamento. Quanto aos malefícios de tal omissão, apenas o fim do período pandêmico poderá evidenciá-los.
} 
Mas se considerada for a atual situação pandêmica, cujo índice de contaminação é altíssimo, bem como sua letalidade, redigir um testamento sem que haja a presença de testemunhas é uma situação possível, levando-se em conta que o testador pode estar em total isolamento social, temendo por sua saúde e de sua família, ou mesmo estar contaminado pelo novo vírus e, com receio de perder a sua vida, organiza seu patrimônio pela via testamentária, mas opta por não querer a presença de ninguém sob responsabilidade de contaminação. Enfim, as possibilidades são várias.

Como requisito de validade, este testador deverá indicar no documento o motivo pelo qual optou por não chamar as testemunhas. Se plausível seus motivos, o juiz poderá determinar a validade - ou não - do contrato.

Quanto a sua validade, o Enunciado $n^{\circ} .611$ da VII Jornada de Direito Civil traz que “O testamento hológrafo simplificado, previsto no art. 1879 do Código Civil, perderá sua eficácia se, nos 90 dias subsequentes ao fim das circunstâncias excepcionais que autorizaram a sua confecção, o disponente, podendo fazê-lo, não testar por uma das formas testamentárias ordinárias ${ }^{6, "}$ (VII Jornada de Direito Civil., 2015).

Entretanto, é passível de apontamento sua principal desvantagem, qual seja a falta de segurança. Tal modalidade testamentária, por se tratar de um caso especial e extremo, realizada sem testemunhas e sem qualquer envolvimento de agentes do Estado, está vulnerável à fraude, extravio, danificação, enfim, situações que comprometem a veracidade e eficácia do instrumento.

Quanto às hipóteses de testamento ordinário viu-se, então, que é possível a escolha deste instrumento jurídico como alternativa ao planejamento sucessório. Embora haja muitos outros institutos jurídicos aptos ao planejamento sucessório, o testamento, principalmente o hológrafo do artigo 1879 do Código Civil, é uma alternativa condizente ao isolamento social.

\footnotetext{
${ }^{6}$ Importa destacar a justificativa do Enunciado $\mathrm{n}^{\circ}$. 611, cuja redação traz o seguinte: "O testamento é negócio jurídico eminentemente solene. O ordenamento jurídico prevê diversas solenidades específicas para cada forma testamentária ordinária ou especial, visando à salvaguarda da liberdade de testar e à preservação da autenticidade das manifestações de vontade do testador. Excepcionalmente, o Código Civil permite que, em circunstâncias extraordinárias (que deverão ser declaradas na cédula), o disponente elabore testamento particular de próprio punho sem a presença de testemunhas. As formalidades são flexibilizadas em função da excepcionalidade da situação em que se encontra o testador, permitindo-se que este exerça sua manifestação de última vontade. Ocorre que, em se verificando o desaparecimento das mencionadas circunstâncias extraordinárias, não se justifica a subsistência do testamento elaborado com mitigação de solenidades. Destaque-se que esta é a regra aplicável para as formas especiais de testamento (marítimo, aeronáutico e militar), para as quais, de modo geral, aplica-se um prazo de caducidade de 90 dias, contados a partir da data em que se faz possível testar pelas formas ordinárias. Por essa razão, conclui-se que, não havendo mais o contexto de excepcionalidade, o testamento hológrafo simplificado perde sua razão de ser, devendo o testador se utilizar de uma das formas testamentárias revestidas das devidas e necessárias solenidades". (VII Jornada de Direito Civil, 2015).
} 
Tanto é que, como será exposto adiante, a busca pela elaboração testamentária tem aumentado desde março de 2020, mês cujo isolamento social se iniciou. Essa afirmação comprova a máxima de que a forma do negócio jurídico não pode ser um fim em si mesma, mas deve atender às demandas sociais que carecem de tutela jurídica (NEVARES, 2020, p. 356).

\section{Popularização do testamento em tempos de pandemia}

O testamento, embora não seja culturalmente popular no país, e isso acontece por vários motivos, como por exemplo o tão temido medo da morte, teve, com a influência da Covid-19, alta procura no último ano.

Esse instituto, se feito na forma ordinária, que é ato personalíssimo, unilateral, gratuito, solene e revogável, pelo qual alguém, segundo as prescrições da lei, dispõe, total ou parcialmente, de seu patrimônio para depois da sua morte, ou nomeia tutores para seus filhos, ou então reconhece filhos naturais, como também pode fazer outras declarações de última vontade (BEVILAQUA, 1944, p. 89), tem suas vantagens escancaradas àqueles que, por medo da morte, preferiram a prevenção contra as brigas familiares ou dilapidação do patrimônio pessoal por meio de um instituto jurídico.

De acordo com os dados reunidos pelo Colégio Notarial do Brasil - Conselho Federal (CNB/CF), mais de 185 mil atos de transferência de bens foram realizados nos últimos seis meses de 2020 - 11 mil a mais do que o mesmo período de 2019. Esse é o segundo semestre que mais teve registros de testamentos, inventários, partilhas e doação de bens nos últimos dez anos (CNB/FC, 2021). No total, foram mais de 19 mil testamentos (CNB/FC, 2021).

Quanto a transferência de bens de um modo geral, os estados que mais se destacaram em relação ao crescimento de registros dessa natureza foram Amapá (75\%), Rondônia (23\%), Maranhão (21\%), Paraná (16\%), Distrito Federal (15\%), Mato Grosso do Sul (15\%), São Paulo (13\%), Roraima (9\%) e Mato Grosso (9\%) (CNB/FC).

Independentemente de suas modalidades, fato é que a pandemia trouxe certa popularização ao testamento, instituto antes pouco usado pelos brasileiros. O número desse documento registrado em Cartórios de Notas em todo o Brasil cresceu de 1249 em abril para 2918 em julho do ano passado. A variação representa um aumento de 134\% e confirma uma percepção que já havia sido relatada por especialistas em abril (CNB/FC, 2020). 
Conforme dados da Associação dos Notários e Registradores do Estado do Paraná ANOREG/PR, houve um aumento de $70 \%$ na procura pela elaboração de testamentos nos cartórios no mês de março de 2020. O maior público no momento retratado era de idosos, embora houvesse aqueles que estivessem garantindo a assinatura do documento sem estar entre o grupo mais vulnerável à doença (ANOREG, 2020).

A busca por elaborar, mediante os institutos jurídicos, como o próprio testamento, a destinação patrimonial, tem mostrado que é necessário pensar em um planejamento sucessório, definir aquele que receberá os bens e expor a autonomia de vontade.

Embora os dados apresentados sejam de testamentos públicos ou mesmo cerrados (não há distinção nos registros apresentados pelo Colégio Notarial do Brasil), o testamento particular também é uma opção cabível à atual realidade. A depender da realidade, local e fase pandêmica decretada pelos estados, o testamento hológrafo simplificado pode ser uma alternativa aos anseios do detentor do patrimônio.

Entre suas vantagens, pode-se apresentar a não dependência do serviço público cartorário; a redação e assinatura pelo próprio testador, podendo ele elaborar o documento em seu próprio tempo; a manifestação pura de última vontade; o baixo custo; e a mudança conforme a conveniência do testador.

Contudo, deve-se apresentar claramente o motivo excepcional que levou o testador a optar por esta modalidade testamentária, bem como ser renovado após 90 dias do fim da situação de urgência caso o testador pretenda dar continuidade ao seu planejamento patrimonial.

Ainda, conforme o exposto, viu-se que o testamento pode ser um instrumento jurídico apto a permitir que todos, independentemente de classe social, profissão, idade, raça ou gênero, façam destinação de seus bens ou disposição de última vontade.

Deve-se, claro, seguir com os requisitos de validade do negócio jurídico, porém, é notável o alívio trazido (especialmente ao se referir ao testamento particular, embora não haja dados demonstrando o alegado) àqueles que buscavam definir a realidade material deixada após sua morte.

Esse movimento de popularização do instituto testamentário tem se mostrado plenamente resolutivo à atual realidade, cuja incerteza sobre a continuidade da saúde e da vida faz morada em vários dos lares brasileiros. 


\section{O testamento como alternativa ao planejamento sucessório e patrimonial}

É no cenário da Covid-19, cujas incertezas acerca da permanência da vida tornam-se cada vez mais comuns, que a necessidade de se planejar não deve ser adiada. Faz parte do ideário brasileiro o tabu ao lidar com a morte, embora essa seja a única certeza sobre a vida (TEIXEIRA, 2019, p. 41). Mas é preciso quebrar tais amarras e pensar na família e nos bens.

Até a última semana do mês de março de 2021, já foram, segundo dados do Coronavírus Brasil (BRASIL, 2021), mais de 12 milhões de casos registrados em todo país, com cerca de 300.000 mil mortes em decorrência da contaminação. No referido mês, um novo recorde fora alcançado, com mais de 3 mil óbitos em apenas um dia. A região Sudeste é a que mais sofre, com mais de 130 mil óbitos.

Ainda, não se deve pensar a pandemia da Covid-19 como um caso raro ou isolado. O mundo tem enfrentando crises sanitárias em ritmos cada vez mais acelerados. Da gripe espanhola (1918), passando pelo vírus H1N1 (2009) até o novo coronavírus (2019), o tempo tem se encurtado, por exemplo. É preciso pensar com isso que uma epidemia "toca todos os domínios da sociedade e desorganiza a vida da cidade, [é] a única que coloca os cadáveres na rua, que muda a tal ponto as mentalidades (BLONDEAU, 1986, p. 80).

O planejamento sucessório e patrimonial surge neste contexto como uma alternativa a tal fatalidade, pois "um adequado planejamento democratiza e internaliza a vontade do autor da herança" (TEIXEIRA, 2019, p. 41). Também, “o planejamento sucessório atende à procura por organização e permite que as pessoas enfrentem a dificuldade humana de lidar com a morte" (TEIXEIRA, 2019, p. 41).

Deve-se, entretanto, desprender-se dos mitos que envolvem o planejamento sucessório, como aquele que o planejamento sucessório é somente para pessoas que detém vasto patrimônio. O planejamento sucessório envolve desde o reconhecimento de um filho, até mesmo a criação de personalidades jurídicas. Tudo depende da pretensão do detentor dos bens, da sua realidade patrimonial e familiar.

No mais, planejar a sucessão quer dizer organizar. Organizar, neste contexto, refere-se a evitar dilapidação patrimonial, lides familiares, gasto de tempo com um processo judicial de inventário e surpresas indesejáveis.

Como função primordial, o planejamento sucessório e patrimonial busca uma atividade "preventiva com o objetivo de adotar procedimentos, ainda em vida do titular da herança, com relação ao destino de seus bens após a sua morte” (TEIXEIRA, S. M. B., 2005, 
p. 06). Não diferente, tem também como escopo a tranquilidade do autor da herança, que em tempos sombrios poderá organizar, por meio de institutos previstos em lei, o que demorou a vida toda para conquistar.

Tal planejamento pode ser realizado com a conjuntura de vários instrumentos jurídicos, a depender da realidade patrimonial e familiar do detentor dos bens. Pode ser instrumento a partilha em vida, a doação, ata notorial, declaração antecipada de vontade, fideicomisso e até mesmo a constituição de pessoais jurídica, como as holdings, offshore, entre outros.

Contudo, não é de se negar que o testamento é o instrumento mais apto ao planejamento sucessório, trazendo vários benefícios, como a antecipação, mas sem imediata execução, da programação do testador. Assim, a vontade do autor do patrimônio é mantida, mas pode ser mudada de acordo com seus interesses ou caso houver variações dos bens, posteriormente. Basta que se elabore outro documento (MULTEDO; MEIRELES, 2019, p. 579).

Ademais, com a insegurança à continuidade da saúde trazida pela nova crise global causada pelo Coronavírus, o testamento permite que o titular dos bens realize a sua organização patrimonial e, posteriormente, caso queira, altere a sua disposição. É possível que isso ocorra, pois o testamento é um ato que dispõe a última vontade, efetivando o princípio da autonomia da vontade. É um ato que alguém dispõe parcial ou totalmente de seus bens para depois de sua morte (TOIGO, 2016, p. 68).

São hipóteses de cabimento do testamento, ainda, compor o direito patrimonial do cônjuge ou companheiro sobrevivente, a depender do regime de bens escolhido; a organização do quinhão dos herdeiros legítimos; a divisão do $50 \%$ disponíveis aos herdeiros testamentários; a atribuição de deveres ou mesmo condições para a transmissão da parcela dos bens; bem como efetuar liberalidades patrimoniais para terceiros (TOIGO, 2016, p. 68).

Mas o ato de testar deve respeitar alguns limites, como a porção reservada à legítima dos herdeiros necessários de 50\% (art. 1845 do CC), que são, respectivamente, os descendentes, os ascendentes e o cônjuge (ou companheiro, conforme os RE $\mathrm{n}^{\circ}$. 646.721 e 878.694).

Também, respeita-se o regime de bens do casamento a que o testador está submetido, pois no caso de haver bens comuns ao casal e eles forem objeto de testamento, ambos devem 
testar ou o(a) testadora(a) apenas poderá dispor de sua parte, não devendo mencionar a parte de seu cônjuge/companheiro(a) (TOIGO, 2016, p. 68).

Ressalva-se, contudo, que o testamento conjuntivo, seja simultâneo, recíproco ou correspectivo é vedado por lei, como traz o artigo 1863 da Carta Civil, por ser o instituto do testamento ato personalíssimo, como mostra o artigo 1858 do mesmo código (BRASIL, 2002).

Não se pode esquivar, porém, da partilha-testamento quanto relaciona-se o testamento ao planejamento sucessório. O artigo 2014 do Código civilista em vigor autoriza o testador a indicar os bens e valores que deseja repartir entre cada um de seus herdeiros, deliberando ele próprio a partilha (MULTEDO; MEIRELES, 2019, p. 580).

Tal vontade deverá prevalecer, já que o artigo em tela prevê a hipótese de o próprio testador indicar os bens e/ou valores que devem integrar as quotas hereditárias, facilitando a fase de liquidação do processo de inventário. Visto isso, tem-se que a proposta do testador corresponde à justa equitativa divisão dos quinhões (LEITE, 2009, p. 415-416).

A partilha-testamento pode alcançar todos os herdeiros legítimos, desde que respeitado, como dito alhures, a proporção dos herdeiros necessários (art. 2014 do CC). Em apertada síntese, pode-se dizer que sua vantagem está no fato de que o quinhão de cada herdeiro não necessariamente precisa ser igual, podendo um receber parcela maior que a de outro.

Exemplo disso é um testador, viúvo, sem ascendentes vivos, sem dívidas, que detém um patrimônio avaliado em um milhão de reais e dispõe em testamento que serão cinco seus herdeiros: dois filhos e três sobrinhos cuja criação ajudou a custear. Um filho receberá um imóvel avaliado em $\mathrm{R}$ \$ 250.000,00, enquanto outro receberá quotas de uma empresada igualmente avaliadas em $\mathrm{R} \$ 250.000,00$. Dois dos sobrinhos receberão bens móveis, em montante igual a $\mathrm{R} \$ 150.000,00$ para cada e um outro receberá a cessão aos direitos autorais avaliada em R $\$ 200.000,00$.

Nota-se que aos filhos, herdeiros necessários, fora respeitado o limite mínimo de $50 \%$ da reserva do patrimônio e aos sobrinhos, por deliberação de última vontade, houve a inclusão na divisão dos bens. Contudo, a cada sobrinho houve uma porção diferente recebida, o que não prejudica a validade do negócio jurídico.

Isso se explica, pois: “A legítima não pode ser prevista em testamento quando a disposição resultar na sua restrição, isto é, não pode ser reduzida na sua essência ou valor por 
cláusula testamentária, pois o direito das sucessões se rege pelo princípio da intangibilidade da legítima" (MULTEDO; MEIRELES, 2019, p. 581). Essa espécie de herdeiro, cujos bens herdados estavam definidos em testamento, é chamada de ex re certa.

Não obstante, importante trazer à reflexão que a rigorosa divisão, que proporciona quotas hereditárias exatamente iguais dos bens, pode levar a uma partilha que não seja benéfica aos herdeiros, por não corresponder aos seus interesses, como também a função social da propriedade. Assim, a partilha deve observar os diferentes interesses e necessidades dos herdeiros (MULTEDO; MEIRELES, 2019, p. 583).

Considerando que o testador, médico, tenha dois filhos, por exemplo, um médico e um outro servidor público, e a sua disposição considerou as profissões de seus herdeiros. Neste caso não parece razoável aquele que é servidor público herdar o consultório deixado pelo pai. Isso porque o patrimônio deve, também, atender as necessidades e comodidades dos herdeiros, fazendo com que haja ao máximo a prevenção contra deterioração patrimonial por um processo de inventário litigioso.

Contudo, adenda-se mais uma vez que, antes de prever em testamento a partilha dos bens, vale reservar o valor da legítima, de acordo com os bens existentes no ato da feitura do documento. Este valor pode variar ao longo do tempo, sendo acrescido ou subtraído (MULTEDO; MEIRELES, 2019, p. 582).

A partir de então, o planejamento sucessório poderá ser realizado. A vontade do testador não é absoluta. Ainda, cabe a ele escolher em partilha-testamento a quem destinará melhor seu patrimônio, considerando preceitos subjetivos e objetivos, tais como a aptidão para administrar determinado bem, bem como se o herdeiro inclui o rol dos herdeiros necessários ou não. Não se trata, portanto, de fazer colidir com a vontade do testador e com a dos herdeiros, pelo contrário, mas da liberdade testamentária que esbarra nos limites do artigo 1846 do Código Civil.

Com a partilha-testamento como cláusula de testamento dentro do planejamento sucessório, é possível evitar litígios, deterioração patrimonial, fazer prevalecer a vontade do testador e até mesmo preservar a boa relação no seio familiar, pois pode abranger todo o espólio.

Com efeito, a partilha-testamento "surge como forma atraente de promoção de uma igualdade substancial entre os herdeiros, por meio do efetivo aproveitamento do patrimônio 
em consonância com as necessidades concretas de cada um" (MULTEDO; MEIRELES, 2019, p. 587).

Assim, torna-se indubitável que a adoção de tal medida preventiva pelo autor do patrimônio em relação à destinação de seus bens visa a sua tranquilidade (pois sabe que suas conquistas ao longo da vida serão mantidas por aqueles que escolheu para delas cuidar), a comodidade dos herdeiros e o atendimento as suas necessidades.

O planejamento sucessório, portanto, realizado por meio do testamento e cláusulas especiais, pode ser um caminho legal à conscientização dos herdeiros sobre os bens deixados, a necessidade de continuidade patrimonial, bem como de cuidado com a boa relação entre os membros da família.

Lado mesmo, frisa-se a importância de adotar alternativas cujos objetivos são o de sanar os anseios, em relação à organização sucessória e também patrimonial, de todos que foram pegos desprevenidos pelo vírus.

Neste caso, o previsto no artigo 2014 do Código Civil é uma possível forma de resolver uma questão de organização sucessória dos que se mantém em isolamento social, ou estão em situações delicadas de saúde, vezes em CTI's, UTI's ou esperando uma vaga nos hospitais lotados com as vítimas da Covid-19, sem a certeza de que continuarão vivendo, desde que respeitando limites legais.

\section{Conclusão}

O Código Civil traz o testamento como um instituto jurídico solene, cujas regras para validades são inúmeras, independentemente de sua espécie. Com isso, o testamento não era alternativa jurídica muito popular entre os brasileiros.

Contudo, é preciso considerar a realidade atual, cujo Coronavírus mudou totalmente a rotina e as pretensões familiares, gerando incertezas quanto à saúde e a vida. Só no Brasil são mais de 300.000 vítimas fatais em decorrência da contaminação do vírus no último um ano. Este estado de calamidade tem tornado as questões quanto à família, aos bens e a continuidade do bem estar uma preocupação latente.

Neste viés, o testamento tem ganhado maior relevância para a organização do patrimônio do titular dos bens. Como mostraram os dados do Colégio Notarial, houve um aumento categórico nos atos de transmissão de bens no último semestre de 2020, o que corresponde a um aumento de 5,94\% em relação ao mesmo período de 2019. 
No que diz respeito aos testamentos em geral, ao todo contabilizou-se 19 mil registros. Este número retrata a popularização do testamento no último ano, e o motivo resta claro: a preocupação com o planejamento sucessório e patrimonial. Todavia, não se sabe qual a espécie de testamento registrada, se é público ou cerrado. Fato é que o testamento tem se apresentado como mecanismo que possa atenuar, mesmo que minimamente, o estado de vulnerabilidade trazido pelo vírus.

Ainda, se observados os meses de abril a junho de 2020, foi possível observar um aumento de 1669 testamentos registrado, o que corresponde a $134 \%$ em relação ao mesmo período de 2019, tornando o instituto testamentário uma alternativa condizente de solução às pretensões daqueles que buscam sanar preocupações com a sucessão no atual período pandêmico.

Entretanto, vale mencionar que o instrumento testamentário deve obedecer a vários requisitos para a sua validade, como dito alhures. Entretanto, a hipótese do artigo 1879 do Código Civil tem se mostrado uma opção àqueles que temem por sair de casa e ir até um cartório registrar um testamento público, ou não podem, por estarem em condições hospitalares delicadas, por exemplo.

Fato é que as especificidades das famílias no curso de tempo atual têm aumentado e cabe ao direito adaptar-se a elas, protegendo as pretensões dos variados sujeitos. É por isso, que o uso do testamento, especialmente do testamento de urgência, chamado hológrafo, ainda mais se junto às cláusulas especiais, como a do artigo 2014 do CC, pode ser uma saída ao planejamento sucessório em tempos de pandemia.

Mas vale mencionar os cuidados que o detentor do patrimônio deve ter quanto a elaboração do documento, independentemente de ser ele público, cerrado, particular ou hológrafo, para que sua pretensão não caia pelo vício de validade.

Cabe ao titular dos bens e da pretensão identificar a existência de herdeiros necessários primeiramente, e depois dos facultativos. Aos herdeiros necessários é reservado obrigatoriamente $50 \%$ do patrimônio. $\mathrm{Na}$ ausência destes, pode o testador dispor da integralidade de seus bens por meio de testamento para qualquer um que ache conveniente, mas se não o fizer, os herdeiros facultativos de até quarto grau herdarão o patrimônio. Também, é pré-requisito que se observe o regime de bens pelo qual o titular dos bens é casado ou vivente de união estável. 
Não existe um padrão preexistente para um testamento. Cada caso tem sua particularidade e o testamento eficaz é o testamento que é adaptado à realidade do testador, dos herdeiros e dos beneficiários. Também, é importante registrar que o testamento é um instrumento que pode ser revogável, alterado a qualquer tempo considerando a vontade do testador.

No que lhe refere, na atual calamidade pública por razões sanitárias, medida de flexibilização quanto aos registros notariais foram tomadas, como a promulgação da Resolução $\mathrm{n}^{\circ} .100$ do CNJ que permitiu o registro remoto de certos documentos, contudo, não foi suficiente à segurança para a transmissão de bens.

Neste viés, a elaboração de testamento ordinário pode corresponder à disposição de última vontade, sendo uma alternativa possível ao planejamento sucessório no cenário pandêmico. Especialmente o testamento hológrafo, cujas formalidades são poucas, faz-se explicitamente como segurança jurídica à expressão e intensão do testador.

\section{REFERÊNCIAS}

ANOREG - Associação dos Notórios e Registradores do Estado do Paraná. Clipping Tribuna do Paraná - Coronavírus aumenta em $70 \%$ a realização de testamentos no Paraná. 2020. Disponível em <http://www.anoregpr.org.br/clipping-tribuna-do-paranacoronavirus-aumenta-em-70-a-emissao-de-testamentos-no-parana/> Acesso: 23.mar.2021.

BEVILÁQUA, Clóvis. Código Civil dos Estados Unidos do Brasil comentado. Vol. VI, $5^{\text {a }}$ Ed. Rio de Janeiro: Livraria Francisco Al, 1944.

BLONDEAU, Marie-Thérèse. Notes pour une édition critique de La Peste. Roman 20-50, n. 2, dez. 1986.

BRASIL, Conselho Nacional de Justiça. Provimento $\mathbf{n}^{\mathbf{0}} 100$ de 26 de maio de 2020. Dispõe sobre a prática de atos notariais eletrônicos utilizando o sistema e-Notariado, cria a Matrícula Notarial Eletrônica-MNE e dá outras providências. Disponível em < https://atos.cnj.jus.br/atos/detalhar/3334> Acesso: 19.mar.2021.

BRASIL. Lei $\mathbf{n}^{\mathbf{0}} \mathbf{1 0 . 4 0 6}$, de 10 de janeiro de 2002. Institui o Código Civil. Brasília, 2002. Disponível em < http://www.planalto.gov.br/ccIVIL_03/Leis/2002/L10406.htm> Acesso: 17.mar.2021.

BRASIL, Ministério da Saúde. Coronavírus Brasil. 2021. Disponível em <https://covid.saude.gov.br/> Acesso: 23.mar.2021.

CAMPOS, Antonio Macedo de. Direito das Sucessões. 2a Ed. Bauru: Jalovi, 1977. 
CNB-FC - Colégio Notorial do Brasil, Conselho Federal. Clipping - Estadão - Com pandemia, cartórios batem recorde no registro de transferência de bens. 2021. Disponível em < https://www.notariado.org.br/clipping-estadao-compandemia-cartorios-batem-recorde-no-registro-de-transferencia-de-bens/> Acesso: 21.mar.2021.

CNB-FC - Colégio Notorial do Brasil, Conselho Federal. Testamentos são tema de destaque no Valor Investe. 2020. Disponível em < https://www.notariado.org.br/testamentos-sao-tema-de-destaque-no-valor-investe/> Acesso: 21.mar.2021.

DINIZ, Maria Helena de. Curso de direito civil brasileiro. Direito das Sucessões. Vol. 6, 19 Ed. São Paulo: Saraiva, 2005.

GONÇALVES, Carlos Roberto. Direito Civil Brasileiro: Direito das Sucessões. Vol. 7, 10 Ed. São Paulo: Saraiva, 2016.

HIRONAKA, Giselda Maria Fernandes Novaes. Curso avançado de direito civil. Direito das Sucessões. Vol. 6, 2ª Ed. São Paulo: RT, 2003.

LEITE, Eduardo Oliveira. Comentários ao novo Código Civil: do direito das sucessões arts. 1.784 a 2.027. Rio de Janeiro: Forense, v. XXI, 2009.

MONTEIRO, Washington de Barros. Curso de direito civil: direito das sucessões. Vol. 06,

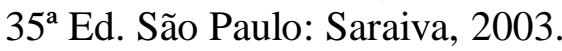

MULTEDO, Renata Vilela; MEIRELES, Rose Melo Venceslau. Partilha da legítima por meio de testamento. In TEIXEIRA, Daniele Chaves. Arquitetura do planejamento sucessório. $2^{\mathrm{a}}$ Ed. Belo Horizonte: Fórum, 2019.

NEVARES, Ana Luiza Maia. Como testar em momento de pandemia e isolamento social. In NEVARES, Ana Luiza Maia; XAVIER, Marília Pedroso; MARZAGÃO, Silvia Felipe (coord.). Coronavírus: impactos no Direito de Família e Sucessões. Indaiatuba: Editora Foco, 2020.

SILVA, Rafael Cândido. Pactos Sucessórios e Contratos de Herança: estudo sobre a autonomia privada na sucessão causa mortis. Salvador: JusPodivm, 2019.

TARTUCE, Flávio; SIMÃO, José Fernando. Direito Civil: Direito das Sucessões. Vol. 6, $6^{\mathrm{a}}$ Ed. São Paulo: Editora Método, 2013.

TARTUCE, Flávio. Manual de direito civil. Rio de Janeiro: Forense, São Paulo: Método, 2011.

TEIXEIRA, Daniele Chaves. Noções prévias do Direito das Sucessões: sociedade, funcionalização e planejamento sucessório. In TEIXEIRA, Daniele Chaves. Arquitetura do planejamento sucessório. 2a Ed. Belo Horizonte: Fórum, 2019. 
TEIXEIRA, Silvia Maria Benedetti. Planejamento sucessório: uma questão de reflexão. Revista Brasileira de Direito de Família, Porto Alegre, ano VIII, no. 31, p. 5-18, ago./set., 2005 .

TOIGO, Daiile Costa. Planejamento sucessório empresarial: proteção patrimonial nacional e internacional. São Paulo: AGWN, 2016.

VELOSO, Zeno. Do testamento particular. In TEIXEIRA, Daniele Chaves (Coord.). Arquitetura do planejamento sucessório. $2^{\mathrm{a}}$ Ed. Belo Horizonte: Fórum, 2019.

VELOSO, Zeno. Novo Código Civil comentado. São Paulo: Saraiva, 2006.

VII Jornada de Direito Civil. Enunciado no . 611. Brasília, novembro de 2015.

VENOSA, Sílvio de Salvo. O testamento particular no Código Civil de 2002. 2015. Disponível em <http://genjuridico.com.br/2015/12/29/o-testamento-particular-no-codigocivil-de-2002/> Acesso: 30.mar.2021 